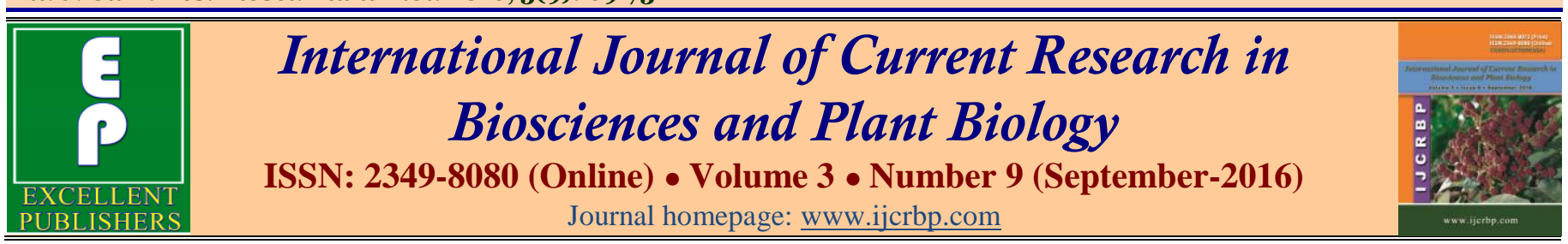

\title{
Isolation and Identification of Phenol Degrading Bacteria from Effluent Treatment Plant of Coir Industry, Kerala, India
}

\author{
V. Rajani, S. Sowparnika* and R. Aswathy \\ PG Department of Environmental Sciences, All Saints' College, Thiruvananthapuram, Kerala, India \\ *Corresponding author.
}

\section{A bstract}

Phenol and its components are extremely toxic and can easily be isolated from different industrial sewage such as oil refinery, petrochemical industry and mines, especially collier and chemical factories. The presence of these compounds in the environment could cause environmental pollution, especially in water resources. Phenol and its components are majorly toxic to the environment. It is hazardous when exposed to the organism's surface. Phenol-degrading bacteria exist widely in the environment, and they are usually isolated from phenol contaminated site. The aim of the study was to isolate and identify the phenol degrading bacteria from effluent treatment plant of coir industry. Bacterial strains capable of degrading phenol were isolated from enrichments containing $50 \mathrm{mg} / \mathrm{L}$ of phenol. From this $50 \mathrm{ppm}$ sample, the strains were transferred and grown in selective sorbitol media. Five potential strains were selected and were subjected to biochemical characterization and were identified as Brucella sp., Aquaspirillum sp., Erwinia sp., Aeromonas sp. and Moraxella sp. The cultures were subjected to phenol tolerance level of minimum medium containing different concentrations of phenol (200 ppm to $1000 \mathrm{ppm}$ ). As the result of the study, it was clear that the selected 5 bacterial strains were able to survive and gave maximum degradation up to $800 \mathrm{mg} / \mathrm{L}$ phenol. From the preliminary analysis, the most potent among the selected were Brucella sp. and Aeromonas sp. This study will help to find out the phenol degraders from effluent treatment plant which can be isolated and cultured in large scale and also can be used in waste management.
\end{abstract}

\section{Article Info}

Accepted: 26 August 2016

Available Online: 06 September 2016

Ke y w o r d s

Brucella sp.

Coir industry

Industrial effluent

Phenol degradation

Total phenol

\section{Introduction}

For a past few years the rate of environmental issues have risen considerably due to various industrial activities .The sources to which these pollutants reach also include water bodies, which is the crucial life source of every living matter. The biodegradation of aromatic substances in the environment with their toxic property and their ability to persist in the environment for a long period of time is now a major concern. Factories, industries and firms that deal with production of coke, coir, leather, paper etc, release large amounts of toxic components to the water bodies in an overwhelming capacity. Toxicity of phenolic compounds inhibits biological treatment or even eliminates sensitive microorganisms from biological wastewater treatment process and significantly reduces the biodegradation of the other components (Yan et al., 2006).

Phenols and their derivatives commonly exist in the environment. These compounds are used as the components of dyes, polymers, drugs and other organic substances. The presence of phenols in the ecosystems is also related with production and degradation of 
numerous pesticides and the generation of industrial and municipal sewages. Some amount of phenols is also formed during natural processes.

These compounds may be substituted with chlorine atoms, may be nitrated, methylated or alkylated. Both phenols and catechols are harmful ecotoxins. The consumption of water containing high phenolic compounds may lead to cancer as it is a susceptible carcinogen. The exposure of phenol and its derivative compounds to human and animals causes liver and kidney damage, central nervous system impairment, diarrhoea and excretion of dark urine (Olujimi et al., 2010; Khare, 2011).

\section{Materials and methods}

Samples from effluent treatment plant of paper industry were collected and serially diluted. Microbial enrichment was done using nutrient broth with different phenol concentrations $(10,20,30,40,50 \mathrm{ppm})$. From the 50 ppm culture, organisms were collected and added to sorbitol agar medium with varying concentrations of phenol (200, 400, 600, 800 and $1000 \mathrm{ppm})$.

\section{Estimation of total phenol}

Estimation of total phenol was carried out the method of (Bray and Thorpe, 1954).

\section{Observation of total growth}

The growth rates of the microbes were observed by spectrophotometric analysis.

\section{Identification of isolates}

Biochemical characterization was done based on Bergey's Manual of Determinative Bacteriology (1994) and Cappuccino and Sherman (1992).

\section{Results and discussion}

Phenol is highly water soluble, and its presence in the water imparts a carbolic odour to the receiving water bodies and can have baleful effects on aquatic as well as terrestrial flora and fauna including human beings (ATSDR, 2008). Hence removal of phenol from the discharged sewage and effluent is highly necessary. Conventional methods for treatment of phenol have their own set of disadvantages; hence biological method is the current choice. Reports on possibility of treatment of phenol bearing waste water using microorganisms are also available (Nandish, 2005). Till date, research communities have focused only on the isolation of microorganisms from the sites contaminated with industrial effluents containing phenol and use them for the treatment of the industrial wastewater.

In the present study, serially diluted effluent of coir industry was transferred to $10,20,30,40$ and $50 \mathrm{ppm}$ phenol having minimal media. From this $50 \mathrm{ppm}$ sample, the strains were transferred and grown in selective sorbitol media. Five potential strains were selected and were subjected to biochemical characterization and were identified as Brucella sp, Aquaspirillum sp, Erwinia sp., Aeromonas sp. and Moraxella sp. (Table 1).

Table 1. Biochemical tests for bacterial isolates.

\begin{tabular}{llcccccccc}
\hline Strains & $\begin{array}{l}\text { Gram } \\
\text { staining }\end{array}$ & $\begin{array}{l}\text { Oxidase } \\
\text { test }\end{array}$ & $\begin{array}{l}\text { Catalase } \\
\text { test }\end{array}$ & $\begin{array}{l}\text { Citrate } \\
\text { utilization }\end{array}$ & $\begin{array}{l}\text { Methyl } \\
\text { red }\end{array}$ & $\begin{array}{l}\text { Voges } \\
\text { Proskauer }\end{array}$ & $\begin{array}{l}\text { Indole } \\
\text { test }\end{array}$ & $\begin{array}{l}\text { Motility } \\
\text { hrea } \\
\text { hydrolysis }\end{array}$ & $\begin{array}{l}\text { Gelatin } \\
\text { hydrolysis }\end{array}$ \\
\hline $\begin{array}{l}\text { Brucella } \text { sp. } \\
\text { Aquaspirilum }\end{array}$ & -cocci & + & + & - & - & - & - & - & - \\
sp. & -cocci & + & + & - & - & - & - & - & - \\
Erwinia sp. & -rod & + & + & - & - & - & - & - & - \\
Aeromonas sp. & -rod & + & - & - & - & - & - & + \\
Moraxella sp. & -cocci & + & + & + & - & - & - & - \\
\hline
\end{tabular}

Total phenol and growth were recorded according to its incubation periods. This study was proceeded in order to find out growth rate of bacteria by using media of concentrations from 200ppm to 1000ppm. Neumann et al. (2004) adapted Pseudomonas strains to high concentrations of phenol (1000 mg/L) and further biodegradation was carried out at a concentration of 500 $\mathrm{mg} / \mathrm{L}$. They opinioned that the cultures could grow by utilizing phenol as a source of carbon and energy. The growth rate and the total phenol degradation for the microbes were given in tables 2 to 6 .

In 200 ppm medium it was observed that Brucella sp. showed highest phenol degradation at 48hrs hrs (0.0057) followed by Aquaspirillum sp. (0.0119), Erwinia sp. (0.0205), Aeromonas sp. (0.0132) and Moraxella sp. (0.0162). The least degradation was showed by Aeromonas sp. for $24 \mathrm{hrs}$ (0.0880) incubation. The 
growth rate was observed highest for Aquaspirillum $\mathrm{sp}$ at $72 \mathrm{hrs}$ of incubation (0.0817) followed by Aeromonas sp.
(0.0777), Brucella sp. (0.0768), Moraxella sp. (0.0757) and Erwinia sp.

Table 2. Total phenol and growth of coir effluent sample (200ppm).

\begin{tabular}{|c|c|c|c|c|c|c|c|c|}
\hline \multirow{2}{*}{ Strains } & \multicolumn{4}{|c|}{ Total phenol (720nm) } & \multicolumn{4}{|c|}{ Growth (600nm) } \\
\hline & 24 hrs & 48 hrs & 72 hrs & 96 hrs & 24 hrs & 48 hrs & $72 \mathrm{hrs}$ & 96 hrs \\
\hline Brucella sp. & 0.0144 & 0.0057 & 0.0220 & 0.0101 & 0.0631 & 0.0063 & 0.0768 & 0.0708 \\
\hline Aquaspirillum sp. & 0.0461 & 0.0119 & 0.0190 & 0.0086 & 0.0634 & 0.0072 & 0.0817 & 0.0752 \\
\hline Aeromonas sp. & 0.0880 & 0.0132 & 0.0265 & 0.0153 & 0.0579 & 0.0054 & 0.0777 & 0.0739 \\
\hline Moraxella sp. & 0.0737 & 0.0162 & 0.0206 & 0.0135 & 0.0540 & 0.0051 & 0.0757 & 0.0755 \\
\hline
\end{tabular}

Table 3. Total phenol and growth of coir effluent sample (400ppm).

\begin{tabular}{|c|c|c|c|c|c|c|c|c|}
\hline \multirow{2}{*}{ Strains } & \multicolumn{4}{|c|}{ Total phenol (720nm) } & \multicolumn{4}{|c|}{ Growth (600nm) } \\
\hline & 24 hrs & 48 hrs & 72 hrs & 96 hrs & 24 hrs & 48 hrs & 72 hrs & $96 \mathrm{hrs}$ \\
\hline Brucella sp. & 0.0647 & 0.0139 & 0.0168 & 0.0087 & 0.0477 & 0.0064 & 0.0658 & 0.0324 \\
\hline Aquaspirillum sp. & 0.0482 & 0.0103 & 0.0144 & 0.0093 & 0.0576 & 0.0067 & 0.0744 & 0.0694 \\
\hline Aeromonas sp. & 0.0888 & 0.0065 & 0.0178 & 0.0134 & 0.0587 & 0.0054 & 0.0754 & 0.0355 \\
\hline Moraxella sp. & 0.0067 & 0.0052 & 0.0277 & 0.0120 & 0.0623 & 0.0051 & 0.0709 & 0.0574 \\
\hline
\end{tabular}

Table 4. Total phenol and growth of coir effluent sample (600ppm).

\begin{tabular}{|c|c|c|c|c|c|c|c|c|}
\hline \multirow{2}{*}{ Strains } & \multicolumn{4}{|c|}{ Total phenol (720nm) } & \multicolumn{4}{|c|}{ Growth $(600 \mathrm{~nm})$} \\
\hline & 24 hrs & 48 hrs & $72 \mathrm{hrs}$ & $96 \mathrm{hrs}$ & 24 hrs & 48 hrs & $72 \mathrm{hrs}$ & $96 \mathrm{hrs}$ \\
\hline Brucella sp. & 0.0772 & 0.0170 & 0.0181 & 0.0106 & 0.0534 & 0.0083 & 0.0755 & 0.0672 \\
\hline Aquaspirillum sp. & 0.0194 & 0.0021 & 0.0169 & 0.0132 & 0.0613 & 0.0079 & 0.0774 & 0.0706 \\
\hline Aeromonas sp. & 0.0702 & 0.0089 & 0.0209 & 0.0078 & 0.0582 & 0.0078 & 0.0688 & 0.0488 \\
\hline Moraxella sp. & 0.0507 & 0.0093 & 0.0096 & 0.0080 & 0.0566 & 0.0090 & 0.0694 & 0.0434 \\
\hline
\end{tabular}

Table 5. Total phenol and growth of coir effluent sample (800ppm).

\begin{tabular}{|c|c|c|c|c|c|c|c|c|}
\hline \multirow{2}{*}{ Strains } & \multicolumn{4}{|c|}{ Total phenol (720nm) } & \multicolumn{4}{|c|}{ Growth (600nm) } \\
\hline & 24 & 48 & 72 & 96 & 24 & 48 & 72 & 96 \\
\hline Brucella sp & 0.0971 & 0.0108 & 0.0250 & 0.0111 & 0.0577 & 0.0051 & 0.0734 & 0.0681 \\
\hline Aquaspirillum sp & 0.0314 & 0.0153 & 0.0230 & 0.0103 & 0.0574 & 0.0080 & 0.0740 & 0.0630 \\
\hline Aeromonas sp & 0.0890 & 0.0226 & 0.0248 & 0.0192 & 0.0561 & 0.0065 & 0.0686 & 0.0647 \\
\hline Moraxella sp & 0.0820 & 0.0230 & 0.0188 & 0.0140 & 0.0555 & 0.0058 & 0.0715 & 0.0488 \\
\hline
\end{tabular}

Table 6. Total phenol and growth of coir effluent sample (1000ppm).

\begin{tabular}{|c|c|c|c|c|c|c|c|c|}
\hline \multirow{2}{*}{ Strains } & \multicolumn{4}{|c|}{ Total phenol (720nm) } & \multicolumn{4}{|c|}{ Growth (600nm) } \\
\hline & 24 hrs & 48 hrs & 72 hrs & 96 hrs & 24 hrs & 48 hrs & 72 hrs & $96 \mathrm{hrs}$ \\
\hline Aquaspirillum sp. & 0.0233 & 0.0077 & 0.0188 & 0.0076 & 0.0559 & 0.0084 & 0.0592 & 0.0465 \\
\hline Aeromonas sp. & 0.0572 & 0.0069 & 0.0200 & 0.0064 & 0.0549 & 0.0072 & 0.0640 & 0.0631 \\
\hline Moraxella sp. & 0.0652 & 0.0134 & 0.0190 & 0.0106 & 0.0594 & 0.0060 & 0.0738 & 0.0434 \\
\hline
\end{tabular}

In 400ppm medium Moraxella sp showed highest phenol degradation at $48 \mathrm{hrs}(0.0052)$ followed by Aeromonas sp (0.0065), Erwinia sp. (0.0100), Aquaspirillum sp. (0.0103) and Brucella sp. (0.0139).The least degradation was observed for Aeromonas sp. (0.0888) at 24hrs incubation. The growth rate was observed highest for Aquaspirillum sp. at $72 \mathrm{hrs}$ of incubation (0.0817) followed by Aeromonas sp. (0.0777), Brucella sp. (0.0768), Moraxella sp. (0.0757) and Erwinia sp. (0.0725).

In 600ppm medium, Aquaspirillum sp showed highest phenol degradation at 48hrs incubation (0.0021) followed by Aeromonas sp. (0.0089), Moraxella 
$\mathrm{sp}(0.0093)$, Erwinia sp. (0.0126) and Brucella sp. (0.0170). The growth rate was observed to be highest for Aquaspirillum sp. at $72 \mathrm{hrs}$ of observation (0.0817) followed by Aeromonas sp. (0.0777), Brucella sp. (0.0768), Moraxella sp. (0.0757) and Erwinia sp. (0.0725).

In 800ppm medium, Erwinia sp showed highest phenol degradation at $48 \mathrm{hrs}$ incubation (0.0092) followed by Brucella sp. (0.0108), Aquaspirillum (0.0153), Aeromonas sp (0.0226), and Moraxella sp. (0.0230). The least phenol degradation was shown by Brucella $\mathrm{sp}$ (0.0971) at $24 \mathrm{hrs}$ of incubation. The growth rate was observed to be highest for Aquaspirillum sp at $72 \mathrm{hrs}$ of incubation (0.0817) followed by Aeromonas sp. (0.0777), Brucella sp. (0.0768), Moraxella sp. (0.0757) and Erwinia sp. (0.0725). Shen and Wang (1993) conducted experiments on simultaneous chromium reduction and phenol degradation in a co-culture of Escherichia coli and Pseudomonas putida. They also reported similar growth pattern with a short lag period, followed by an exponential growth phase and then a declining growth phase. In 1000ppm medium the phenol degradation rate was highest for Erwina sp. (0.0061) followed by Aeromonas sp. (0.0064), Aquaspirillum sp. (0.0076) Brucella sp. (0.0091) and Moraxella sp. (0.0106). The growth rate was observed highest for Moraxella sp. at $72 \mathrm{hrs}$ of incubation (0.0738) followed by Brucella sp. (0.0718), Aquaspirillum sp. (0.0592), Erwinia sp. (0.0649) and Aeromonas sp. (0.0640).

As the result of the study, it was clear that the selected 5 bacterial strains were able to survive and gave maximum degradation up to $800 \mathrm{mg} / \mathrm{L}$ phenol. Regina et al. (2004) studied the behavioural patterns of hydrocarbon utilizing bacteria in media containing different concentrations of crude oil. They showed that lower doses of crude oil were more highly utilized than higher doses. They accounted this for the high growth response in the low dose of crude oil. From the preliminary analysis, the most potent among the selected were Brucella sp and Aeromonas sp. This study will help to find out the phenol degraders from effluent treatment plant which can be isolated and cultured in large scale and also can be used in waste management.

\section{Conclusion}

The coir-retting environment harbours a variety of potential microbes which can degrade phenols. The growth and adaptability of these bacteria in environment containing phenolic compounds have induced their biodegradation potential (Reshma et al., 2004). Phenolics, one of the major pollutants, are discharged in the waste water from the various industries such as phenolic resin and pharmaceuticals, oil refineries, petrochemical plants, textile industry, ceramic plants, steel plants, and coal conversion processes. The degradation performance of selected strains was examined for different phenol concentrations. Serial exposure to increasing level of phenol concentration was used to determine the resistance of isolated strains. Acclimatization of the microorganisms overcomes the substrate inhibition problems that normally occurred in phenol biodegradation at high concentration (Lob and Tar, 2000). The experiment aimed to find the highest tolerance level of phenol concentrations and found that it was able to survive and degrade up to $800 \mathrm{mg} / \mathrm{L}$ phenol. The growth of bacteria and phenol concentration in the media showed the inverse proportion with each other. From this preliminary analysis, the most potent were Brucella sp and Aeromonas sp. They showed high degradation potential in most of the higher phenol concentrations.

Effluent from waste treatment plant of Coir industry contains a variety of substances including phenolic components. Serial exposure to increasing level of phenol concentration can be used to determine acclimatisability of a particular isolate. Highly acclimatisable microbes are those which are able to degrade phenol at high concentration and at greatest rate will be the best phenol degrader candidates. Future studies should be carried out to isolate more potent useful microbes.

\section{Conflict of interest statement}

Authors declare that they have no conflict of interest.

\section{Acknowledgement}

The authors are gratefully acknowledging the financial support from the University Grants Commission (UGC), for this study in the form of Minor Research Project.

\section{References}

Agency for Toxic Substances and Disease Registry (ATSDR), 2008. Toxicological profile for Manganese. U.S. Department of Health and Human Services, Public Health Service. Atlanta, GA.

Bergey's Manual of Determinative Bacteriology, 1994. John G. Holt, Lippincott Williams and Wilkins.

Cappuccino, J.G., Sherman, N., 1992. Biochemical activities 
of microorganisms. In: Microbiology, A Laboratory Manual. The Benjamin / Cummings Publishing Co., California, USA.

Khare, P., 2011. Treatment of phenolic water using adsorption. Thesis, National Institute of Technology, Department of Chemical Engineering, Rourkela.

Bray, H. G., Thorpe, W. V., 1954. Analysis of phenolic compounds of interest in metabolism. Meth. Biochem. Anal. 1, 27-52.

Lob, K.C., Tar, P.P., 2000. Effect of additional carbon sources on biodegradation of phenol. Bull. Environ. Contam. Toxicol. 64, 756-763

Nandish, M. S., 2005. Microbial Degradation of Phenol and Pentachlorophenol. A thesis, University of Agricultural Sciences, Dharwad.

Neumann, G., Teras, R., Monson, L., Kivisaar, M., Schaver, F., Heipieper, H.J., 2004. Simultaneous degradation of atrazine and phenol by Pseudomonas sp. strain ADP: Effects of toxicity and adaptation. Appl. J. Environ. Microbiol. 70, 1907-1912.

Olujimi, O.O., Fatoki, O.S.., Odendaal, J.P., Okonkwo, J.O.,
2010. Endocrine disrupting chemicals (phenol and phthalates) in the South African environment: a need for more monitoring. Water SA. 36(5), 671-682.

Regina, A., Kosar-Hashemi, B., Li, Z., Rampling, L., Cmiel, M., Gianibell, C., Konik-Rose, C., Larroque, O., Rahman, S., Morell, M.K., 2004. Multiple isoforms of starch branching enzyme I in wheat: lack of the major SBE-I isoform does not alter starch phenotype. Funct. Plant Biol. 31, 591-601.

Reshma, J. K., Salom Gnana Thanga, V., Anu Mathew, 2014. Phenol degradation by bacteria isolated from coir retting beds of south Kerala coast. J. Glob. Biosci. 3(6), 935940.

Shen, H., Wang, Y.T., 1993. Characterization of enzymatic reduction of hexavalent chromium by Escherichia coli ATCC 33456. Appl. Environ. Microbiol. 59(11), 37713777.

Yan, J., Jianping W., Jing, B., Daoquan, W., Zongding, H., 2006. Phenol biodegradation by the yeast Candida tropicalis in the presence of mcresol. Biochem. Eng. J. 29, 227-234.

\section{How to cite this article:}

Rajani, V., Sowparnika, S., Aswathy, R., 2016. Isolation and identification of phenol degrading bacteria from effluent treatment plant of coir industry, Kerala, India. Int. J. Curr. Res. Biosci. Plant Biol. 3(9), 69-73. doi: http://dx.doi.org/10.20546/ijcrbp.2016.309.010 